\title{
Ultrastructure of plasma cells containing Russell bodies in human stomach and thyroid
}

\author{
A. GRAY AND I. DONIACH \\ From the Department of Morbid Anatomy, Institute of Pathology, The London Hospital
}

SYNOPSIS The fine structure is illustrated of plasma cells containing Russell bodies. The material is from chronic inflammatory cell infiltrates in human gastric mucosa and thyroid glands in Graves' disease and Hashimoto's thyroiditis. It is noted that the Russell bodies lie in distended cisternae of rough endoplasmic reticulum and are easily distinguished from less electron-dense 'secretory granules' covered by a smooth membrane that are situated in the Golgi complex.

Plasma cells containing Russell bodies have been noted by light microscopy in chronic infections and granulomata, in normal intestinal mucosa, in chronic inflammatory cell infiltrates associated with malignant tumours, and in plasmacytomas (Pearse, 1949). The bodies give a positive periodicacid Schiff (PAS) staining reaction (Pearse, 1949). They have been observed in the spleen and lymph nodes of mice given repeated intravenous injections of organisms or foreign proteins (White, 1954; Humphrey and White, 1964). Electron micrographs of plasma cells containing Russell bodies have been recorded in experimental animals (Stoeckenius, 1957; Thiery, 1958; Movat and Fernando, 1962) and in biopsies of human gingiva and gastric mucosa (Rifkind, Osserman, Hsu, and Morgan, 1962; Welsh, 1962) and scleroma (Friedmann, 1966). In both animal and human material it was noted in all cases that the bodies were situated in distended cisternae of rough endoplasmic reticulum.

During the electron microscopic examination of chronic inflammatory cell infiltrates in surgical material from gastric mucosa in chronic gastritis and thyroid in hyperthyroidism and Hashimoto's thyroiditis we have observed occasional plasma cells with intracytoplasmic electron-dense bodies lying within the rough endoplasmic reticulum. The bodies vary in diameter from 0.2 to 1.5 microns. Light microscopy of serial sections, Received for publication 9 February 1970.
$0 \cdot 3 \mu$ thick, stained with toluidine blue, from the same material as that used for electron microscopy show unequivocal intercellular and intracellular Russell bodies.

\section{Material, Methods, and Findings}

The electron micrographs (Figs. 1-5) illustrate plasma cells containing these bodies as they occurred in some examples of human immunological reactions, including autoimmune disease.

In all cases the material was freshly fixed in $2.5 \%$ phosphate-buffered glutaraldehyde, $p \mathrm{H}$ 7.4 , at $4^{\circ} \mathrm{C}$, postfixed in Palade's $1 \%$ osmium textroxide, dehydrated, and embedded in Araldite. Sections were stained with uranyl acetate and examined with an AEI-EM6B electron microscope.

\section{Discussion}

Plasma cells secrete immunoglobulin whose freshly synthesized protein appears as slightly electron-dense flocculent material in the lumen of the rough endoplasmic reticulum. The immunoglobulin nature of this material was confirmed by Rifkin et al (1962) using a ferritin conjugated 
antibody technique and by Leduc, Avrameas, and Bouteille (1968) using a horseradish peroxidase technique. Slightly more electron-dense material, the small 'secretory granules' (Ham, 1965), is seen in the Golgi apparatus (Fig. 4). Movat and Fernando (1962) identified secretory 'globules' in the Golgi apparatus in electron micrographs and found them to stain particularly well with silver methenamine after periodic acid oxidation. The Russell bodies are much more electron dense than the secretory granules, are larger, and do not filp the lumen of rough endoplasmic reticulum (Fig. 1)음 The immunoglobulin nature of Russell bodies. was demonstrated by White by light microscopys? using an immunofluorescent technique (Humb phrey and White, 1964). Welsh (1962) showe

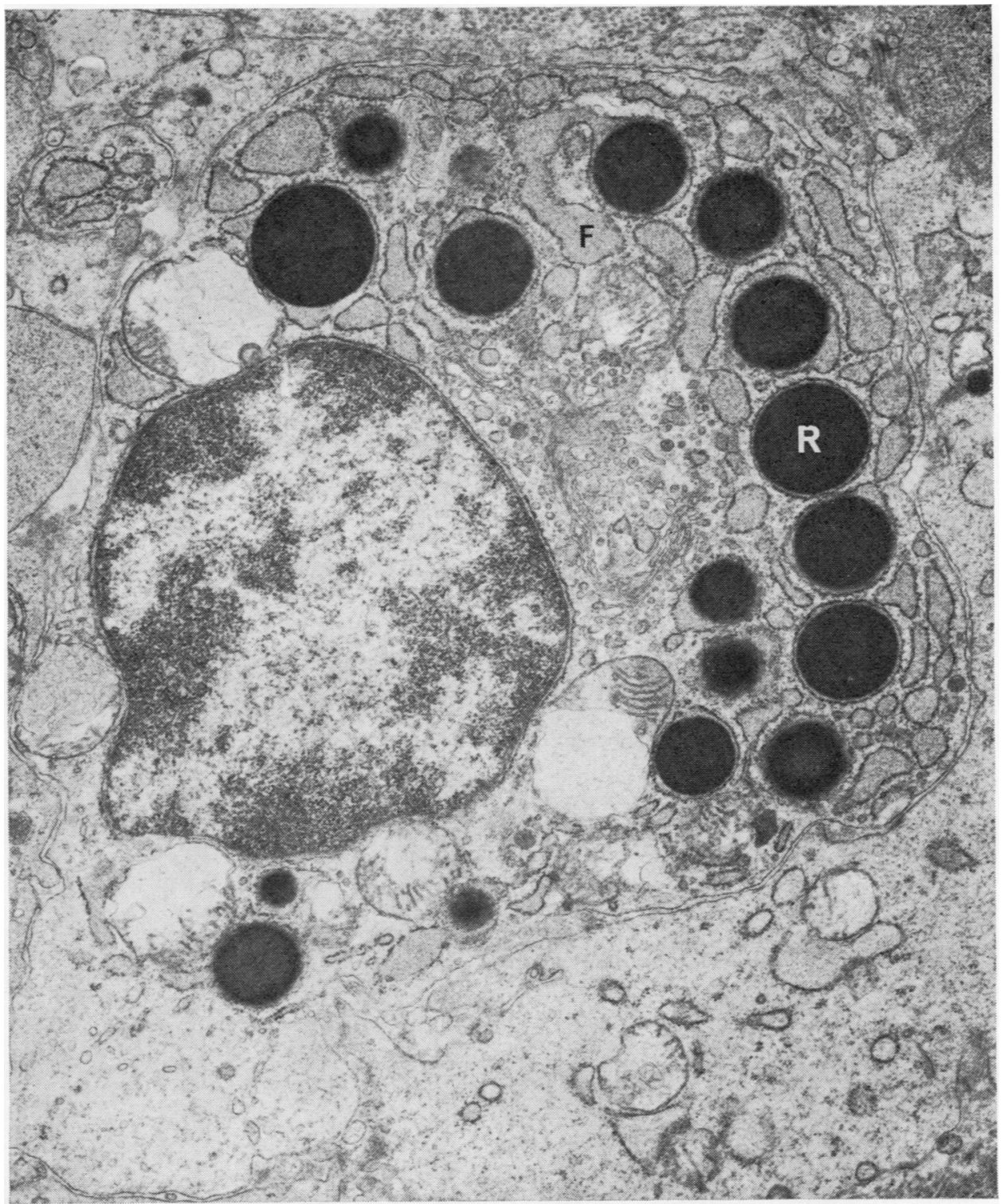

Fig. 1 Chronic gastritis, partial gastrectomy in a male, aged 58. The rough endoplasmic reticulum is distended with fine flocculent material $(\mathrm{F})$ and in places with uniformly very electron-dense spherical droplets of varying size not completely filling the cross-section of the cisternae, presumed intracellular Russell bodies (R). There are no bodies in the Golgi apparatus. $\times 15,000$. 


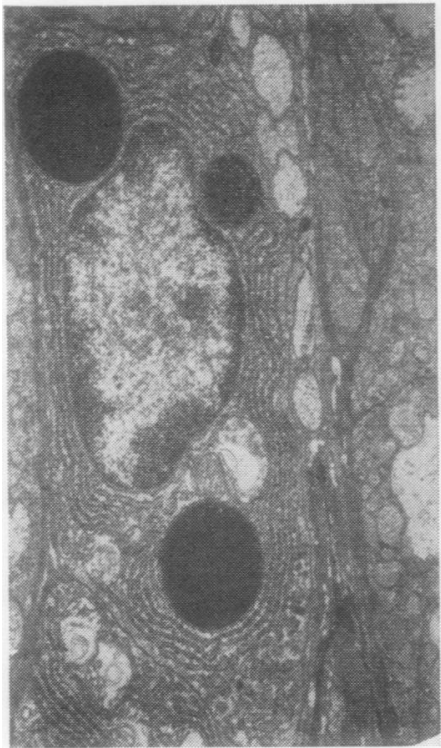

Fig. 2a.

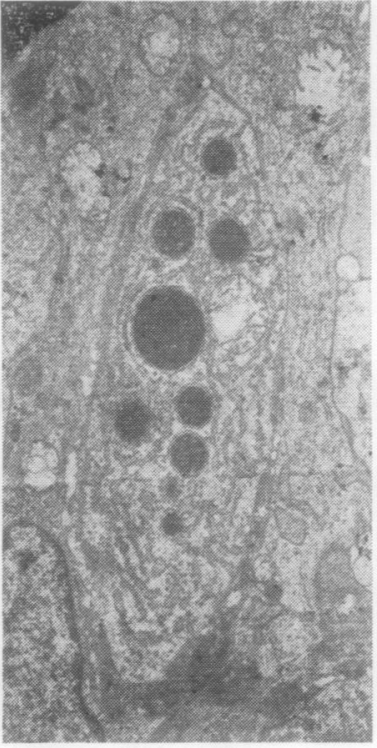

Fig. 2b

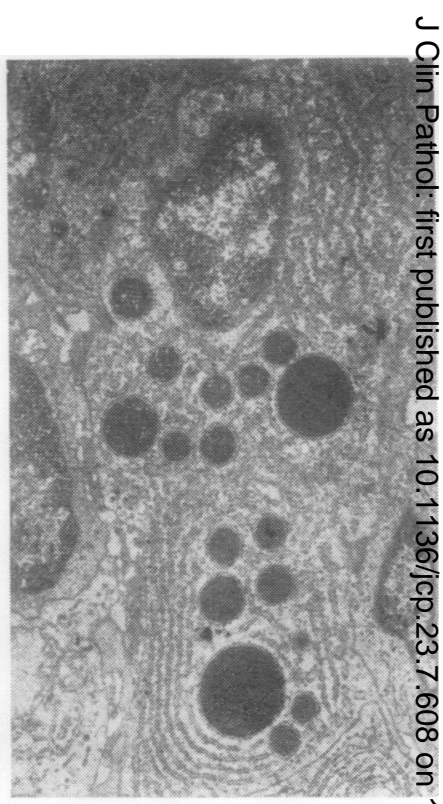

Fig. 2c

Fig. 2 Thyroid in Graves' disease, specimen from thyroidectomy in a female aged 11. Three plasma cells show similar bodies within rough endoplasmic reticulum with considerable variation in the sizes of the bodies in the plane of section. The remaining endoplasmic reticulum shows little filling with secretion. $\times 7,500$.

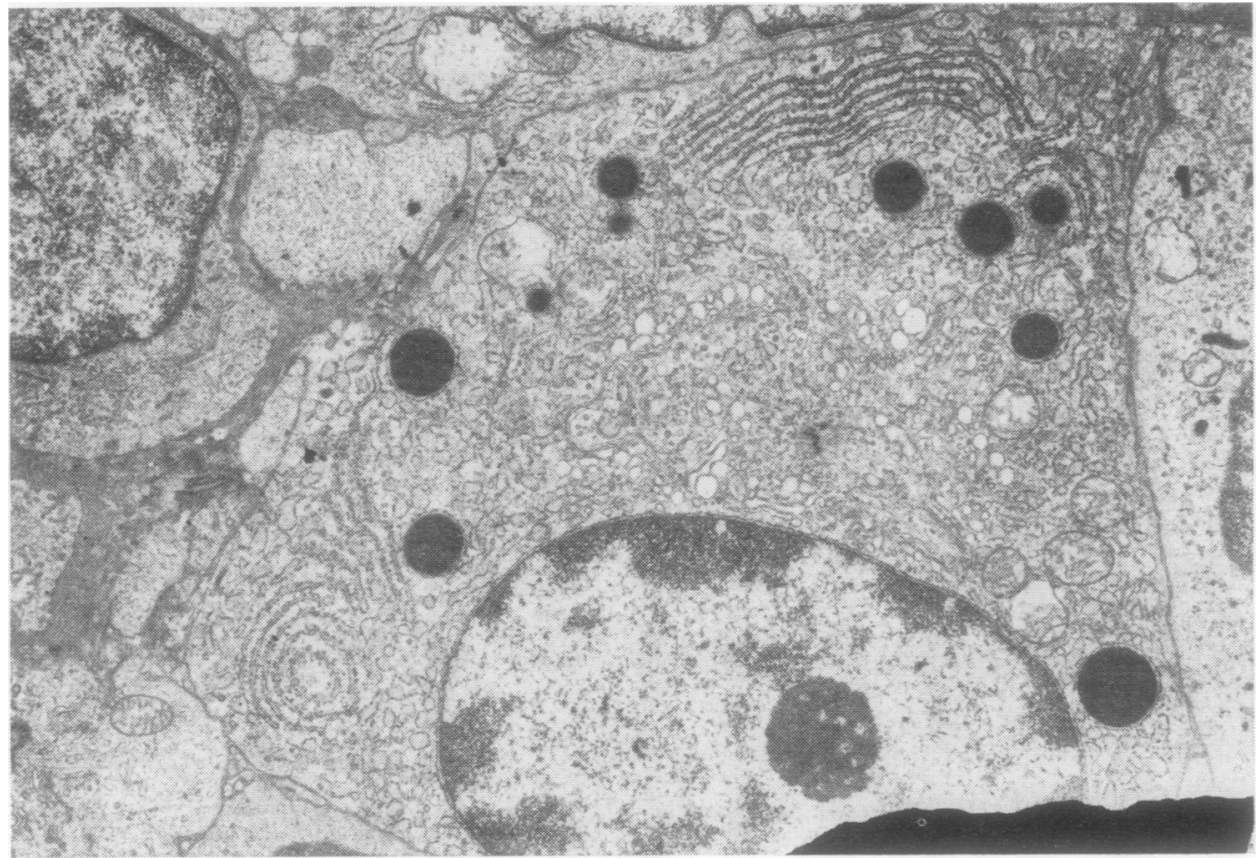

Fig. 3 Thyroid in Hashimoto's thyroiditis, specimen from a subtotal thyroidectomy in a female aged 56. Similar bodies in a plasma cell. They are absent from the large Golgi apparatus. $\times 10,000$. 


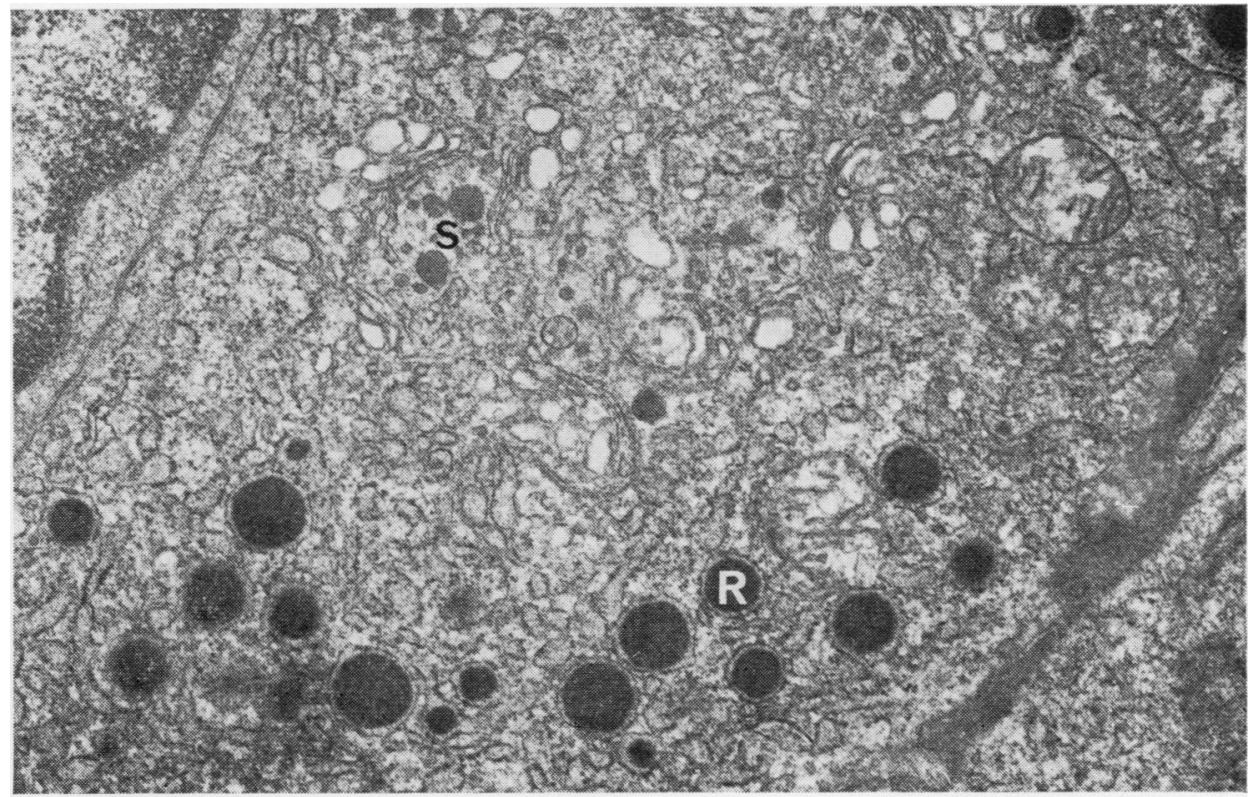

Fig. 4 Thyroid in Hashimoto's thyroiditis (same case as in Figure 3). Similar bodies are seen in the rough endoplasmic reticulum peripherally. There are a few slightly smaller and less electron-dense bodies in the region of the Golgi apparatus, surrounded by smooth membrane; these are of the 'secretory granule' type (S). $\times 20,000$.

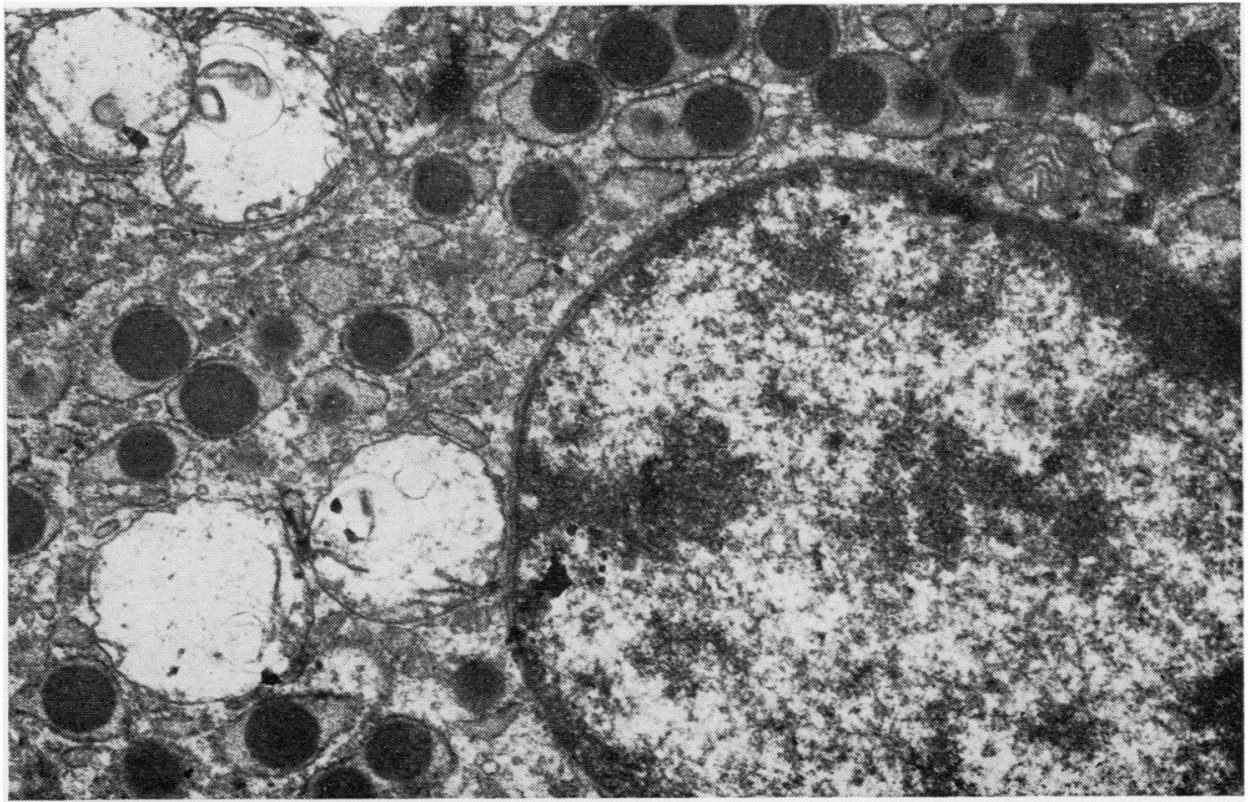

Fig. 5 Chronic gastritis (same case as Figure 1). A plasma cell shows marked distension of rough endoplasmic reticulum with one to four dense bodies in a single profile. $\times 15,000$. 
that the dense bodies lying within the rough endoplasmic reticulum correspond in serial section to the PAS-positive Russell bodies of the light microscope.

It is important to note that Russell bodies differ from the normal 'secretory granules' in the Golgi apparatus covered by a smooth membrane; they are larger, much more electron dense, and lie in distended, rough endoplasmic reticulum. Whether they have a specific function or reflect a pathological process is open to question. Their formation in chronic inflammations and in hyperimmunization might represent a degenerative process, although against this is the otherwise normal appearance of the cell nucleus and cytoplasm.

A puzzling feature is the site of the Russell bodies within the cells since their constituents include carbohydrate. It is generally accepted (Ham, 1965) that in the synthesis of glycoproteins the carbohydrate moiety is added in the Golgi apparatus to protein shuttled there after synthesis in cisternae of the rough endoplasmic reticulum. The secretion thus formed is transported via secretory vacuoles to the plasma membrane where it is liberated by reverse pinocytosis. The presence therefore of glycoprotein in the form of Russell bodies within rough endoplasmic reticulum suggests either a reversal of direction of flow from the Golgi apparatus or that carbohydrate has been added within the rough endoplasmic reticulum. In either case the finding appears to indicate a functional disturbance of plasma cells associated with $\frac{\varrho}{\bar{F}}$ prolonged or hyperactive secretion of immunoglobulin.

We are grateful to Mr J. E. Richardson, surgeon to The London Hospital, for kindly providing the fresh tissues.

References

Friedmann, I. (1966). In Systemic Pathology, edited by Wright and W. St. C. Symmers, Vol. I. p. 296. Longmans, $\vec{O}$ London.

Ham, A. W. (1965). Histology, 5th ed. Pitman, London; Lippin- $\overrightarrow{\vec{\omega}}$ cott, Philadelphia.

Humphrey, J. H., and White, R. G. (1964). Immunology for Students of Medicine, 2nd ed., Fig. 4. 6A. Blackwell, Oxford.

Leduc, E. H., Avrameas, S., and Bouteille, M. (1968). Ultra- ${ }_{\omega}$ structural localization of antibody in differentiating plasma cells. J. exp. Med., 127, 109-118.

Movat, H. Z., and Fernando, N. V. P. (1962). The fine structure of connective tissue II. The plasma cell. Exp. molec. Path., 1, 535-553.

Pearse, A. G. E. (1949). The nature of Russell bodies and Kurloff bodies: Observations on the cytochemistry of plasma cells and reticulum cells. J. clin. Path., 2, 81-90.

Rifkind, R. A., Osserman, E. F., Hsu, K. C., and Morgan, C. (1962). The intracellular distribution of gammaglobulin in a mouse plasma cell tumor (X5563) as revealed by fluor- 吕 escence and electron microscopy. J. exp. Med., 116, 423- $\overrightarrow{-1}$ 432.

Stoeckenius, W. (1957). Weitere Untersuchungen am lymphalischen Gewebe. Ver. dtsch. Ges. Path., 41, $304 \cdot 312$.

Thiéry, J. P. (1958). Etude sur le plasmocyte en contraste de $\square$ phase et en microscopic electronique. III. Plasmocytes à corps de Russell et à cristaux. Rev. Hêmat., 13, 61-78.

Welsh, R. A. (1962). Light and electron microscopic correlation of periodic acid-Schiff reaction in the human plasma cell. Amer. J. Path., 40, 285-296.

White, R. G. (1954). Observations on the formation and nature (\$) of Russell bodies. Brit. J. exp. Path., 35, 365-376. 